\title{
Analysis and Analog Simulation of the Investors' Margin Trading Behavior
}

\author{
Bo Zhang ${ }^{1 *}$, Xueting $\mathrm{Cao}^{1}$ and Allen Yang $^{2}$ \\ ${ }^{1}$ School of economics and management, Xi'an University of Technology, Shaanxi, P. R. China; \\ ${ }^{2}$ University of Toronto, Toronto Canada \\ *Corresponding author
}

\begin{abstract}
This paper took investors' margin trading behavior as the object of study and suggested the hypothesis that the behavioral financial factors would increase market volatility and affected investors' returns in the environment of margin trading system through theoretical analysis. On the basis of the hypothesis, this paper used the data of margin trading of A stock market in China to carry out measurement test, and indicated that investors' margin trading behavior existed significant overconfidence, disposal effect and herd effect. Further, this paper constructed artificial stock market and carried out analog simulation of the investors' margin trading behavior, which shows that the introduction of margin trading system increases the market risk to a certain extent, but it also can be reduced by pre-learning process. Meanwhile, it can be found that the introduction of margin trading increases the returns of fundamental analysis traders, technical analysis traders and noise traders in varying degrees. Compared with other traders, the trend trading strategy adopted by technical analysis traders who make use of excessive market volatility to gain higher income in the margin trading transaction under the incomplete and effective market background.
\end{abstract}

Keywords-margin trading; behavioral finance; analog simulation

\section{INTRODUCTION}

By the end of June 2017, there were a total of 970 stocks on the basis of margin trading in the A share market. The margin trading accounted for nearly $10 \%$ of the share market and the role of the margin trading in the stock market could not be underestimated. At the same time, the main body of margin trading transactions in China's securities market is based on individual investors. At the end of February of 2017, the total number of account opening accounts for 4 million 280 thousand households, of which the number of individual investors accounts for $99.75 \%$. In order to hedge the risk that may be formed by the leverage and short function of the margin trading transactions, China has set up a high threshold for investor access in the current margin trading system design. Behavioral finance research shows that investors, especially individual investors, tend to exhibit irrational characteristics when trading. These investors, who have relatively strong capital strength and rich investment experience to reach the threshold of the margin trading, are still irrational behaviors in the margin trading transactions? If they have irrational behaviors, how will it affect stock price volatility and investors' returns? The answers to these questions depend on the further analysis of investors' margin trading behavior. Therefore, this paper tries to simulate a stock market through the construction of artificial stock market on the basis of the analysis of the investor margin trading behavior, thus depicting a real margin trading process and revealing its market impact.

The research on the margin trading transactions is infancy through combing the existing literature, but there is still a certain number of research results on the simulation of investor behavior and stock market for reference.

\section{A. Research on Investor Behavior}

In the study of disposal effect, the extant literature has two contrasting views on this relationship. The first view is that individual investors tend to hold the loss stocks and sell the profit stocks, indicating the disposition effect of the individual investor's stock trading behavior. Odean calculates the actual profit ratio and the actual loss ratio based on the 162948 transactions records [1], and the research of Frazzini argues that there is also a disposition effect in institutional investors' transactions [2]. Rau further compares the investment behavior of institutional and individual investors and concludes that institutional investors have more disposal effects than individual investors in the process of investment [3]. The second view is that investors generally prefer to hold profit stocks and sell loss stocks on the basis of the choice of stocks that have book loss but a favorable performance and have a book profit but poor performance in the near future. Kaustia supports this view. The conclusion is contrary to the previous research [4].

In the study of investor overconfidence, scholars generally believe that investors are overconfident. Yang Qing draws on the method of Odeans and chooses the account data of all individual investors in a securities business department. The result indicates that there is a general tendency of overconfidence in our individual investors [5]. Tan analyses investor transactions data between January 1999 and December 2003 and finds that favorable historical investment gains will increase the degree of overconfidence of investors through self-attribution bias, but the impact of investment experience on excessive trading is not significant [6]. Liao selects the daily transactions data of 16990 individual investors from January 2006 to June 2009 and measures overconfidence by the early excess net income of investors, and also finds that investors generally have overconfidence [7].

In the study of herd effect, Liu Bo selects the relevant data of Shanghai and Shenzhen two cities from January 1993 to December 2000 respectively. Through two indexes of CSSD and $C S A D$ to test the existence of the herd effect in China stock market, the results show that there is a significant herd effect in 
the stock market [8]. Li uses Top View investor's position and diurnal data of account change to analyzes the difference of herding behavior between institutional and individual investors. It finds that the herding behavior of institutional investors in China is more obvious than individual investors [9]. Cheng finds that the domestic and foreign institutional investors generally have herding behavior in China A share market, and foreign institutional investors tend to follow the domestic institutional investors [10] through the expansion of the measure model of herd behavior.

\section{B. Research on Simulation of Stock Market}

Arthur believes that stock market has nonlinear characteristics, investors are limited rational and can adapt to the environment, and computer simulation of the operation of the stock market is proposed. The establishment of SFI-ASM have pioneered the multi Agent design in the framework of computational finance and provided a unified simulation platform for subsequent research [11]. Yang and Ma include the fuzzy decision learning strategy in the construction of artificial stock market model and use sensitivity analysis and historical data to teste and correct the model [12]. Zou constructs artificial stock market based on the characteristics of Chinese stock market by calculating experimental methods and study the influence of different dividend payments to stock price under the mechanism of two-way auction [13]. Wu constructs a two-way and continuous competitive artificial stock market, in which investors are limited, and their investment decisions will be influenced by stock value, price trend and noise factors [14].

\section{THEORETICAL ANALYSIS}

Based on the hypothesis of market effectiveness, modern financial theory believes that when information enters the market, the homogeneous and rational investors can make a consistent and correct evaluation of the information in the market and integrate information into the stock price fully and in time through the frictionless arbitrage. In reality, according to Liu and Cui [15], there are certain differences and costs in the market information acquisition, and the arbitrage constraints in the market can only achieve limited arbitrage. At the same time, combined with the view of Chi and Zhuang [16], it shows that the investors in the market are neither completely rational nor completely irrational, but a kind of "realistic" investors with behavioral characteristics, and there will be certain cognitive deviations and psychological deviations. The view of "institutional neutrality" in the effective market is questioned in reality, so the introduction of the margin trading system may have an impact on the stock market and the investors.

Generally speaking, when the favorable news enters the market, due to investors are heterogeneous, the interpretation of the same information will also be different. The basic analysis traders are based on the correct information interpretation to produce the arbitrage transactions demand and buy more stocks in the capital budget. The technical analysts still inclined to maintain existing market judgment and will not actively participate in the stock market transactions including margin trading; noise traders may be randomly involved in financing or margin trading based on misinterpretation of information and irrational trading motivation. Therefore, under the expectation of market heterogeneity formed by the difference of traders, the size of the margin trading will increase because of the favorable news, and the increase in the scale of financing transactions is more significant. Stocks price has been pushed up along with favorable information. On the one hand, the basic analysis traders and noise traders who have participated in the purchase of financing, will produce a certain degree of self-attribution bias and control illusion, and then produce overconfidence. The emergence of this psychological bias will also increase investment and further enhance the scale of financing transactions. On the other hand, based on the rising trend of market prices, technical analysts tend to follow the trend, and further stimulate the increase in the scale of financing transactions by buying stocks or financing to buy stocks. At the same time, the noise traders sold the margin in the process of adverse price fluctuations and had lost, due to the disposal effect on the loss position, noise traders who participate in short selling will not significantly reduce their margin trading and may even be based on further expansion of the market heterogeneity, as well as the overconfidence of self-attribution deviation, and further increase the market divergence. With the continuous rising of the stock price and a clear upward trend, the price positive feedback in the market has produced more and more overconfidence to stimulate the investors and attract new investors to enter the market. Then the market and the margin trading have a remarkable herd effect, that is, the scale of financing transactions is rising constantly. On the contrary, the margin trading is shrinking. At this stage, according to the expected idea of Louwers [17], as the stock price goes high, the investor's cognitive bias will form the excessive attention to the favorable news and the market falls into a cycle of anticipation and market positive feedback and forms the expected selfrealization. When the market price is rising, the bubble composition in the stock price is constantly accumulating and expanding, on the one hand, the basic analysis trader is inclined to settle the profit position of the financing transactions because of the disposal effect; On the other hand, the market will be empty when the value is rationally judged, which will lead to a decline in demand for financing transactions and a rise in demand for margin trading. However, technical analysts tend to continue to follow the trend and expand the scale of financing transactions. Due to the existence of herd effect and stock price overshoot in the market, the stock price bubble will usually expand further before it breaks up. Therefore, the basic analysis trader will bear the loss of short selling loss caused by the excessive rising of the market price in this stage. But technical analysts will gain more from financing transactions during the stock bubbles, which is supported by Chen and Ma [18]. When the incremental funds produced by the herd effect and the leveraged funds generated by the financing transactions push the stock price further away from the intrinsic value of the stock, the market inevitably increases and the market fluctuation increases obviously, which has been confirmed in the study of $\mathrm{Xu}$ [19][20]. When these funds are insufficient to continue to support the stock market bubble, the bubble will eventually be difficult to sustain and then burst asset price bubbles. The basic analysis trader's margin trading position will get the profit at this time and stimulate the scale of margin trading, and the technical analyst will reduce the scale of financing transactions because of the loss of financing transactions. In the downward trend of asset price bubble, there will be obvious changes in the 
margin trading under the same logic. This process can be based on information impact to produce margin trading and market

fluctuations (Figure 1).

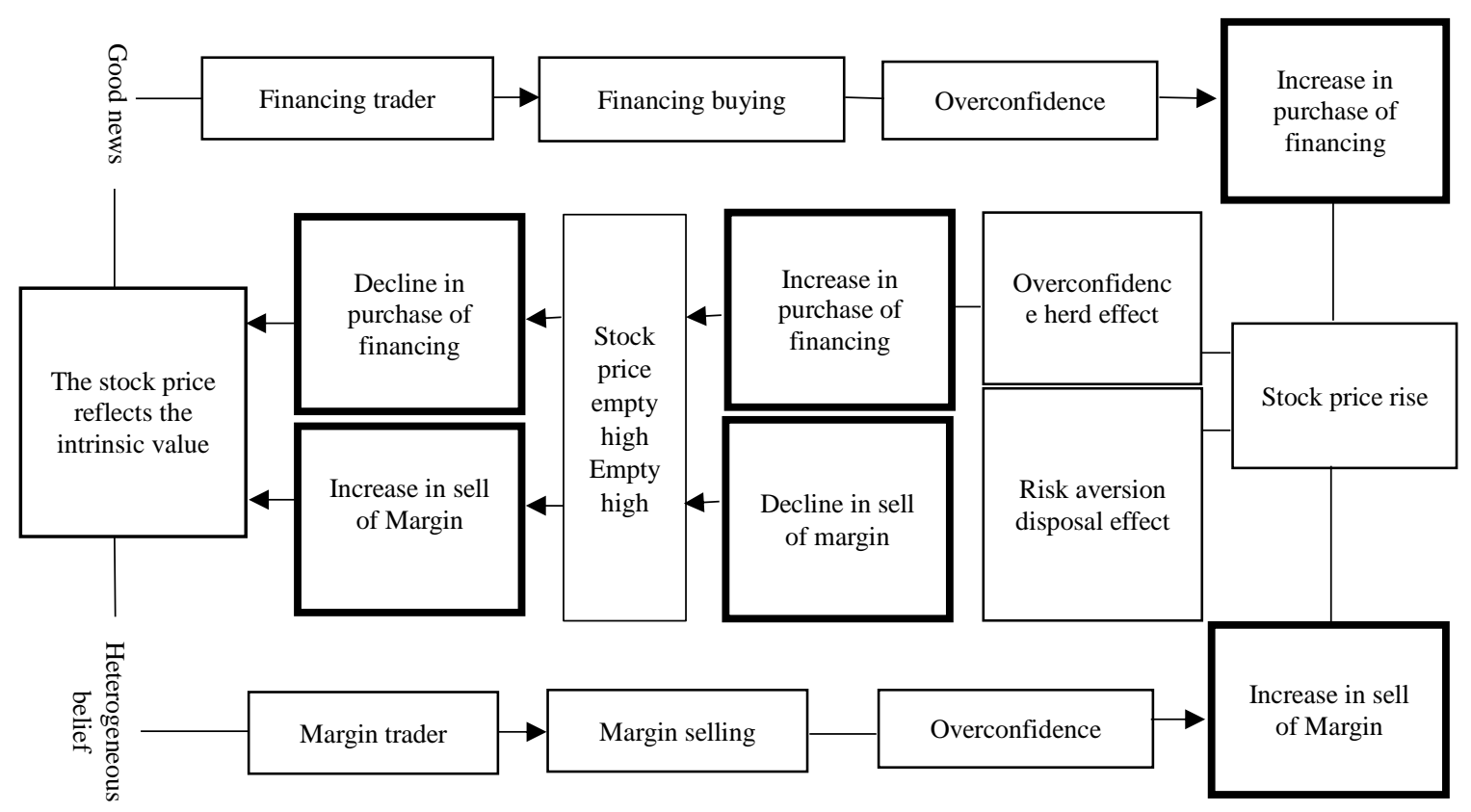

FIGURE I. THEORETICAL ANALYSIS ON INVESTOR'S MARGIN TRADING BEHAVIOR

\section{INVESTORS’ MARGIN TRADING BEHAVIOR TEST}

\section{A. Sample Selection}

In September 23, 2014, the margin trading standard was expanded in fourth times, and it was also the last expansion at present. Therefore, the research starting point is selected in September 23, 2014. Considering the comprehensiveness of the study, the research period is required to cover different market conditions. September 30, 2015 is selected as the end point of the study. It includes a clear, basic symmetry of the rising and falling trend of the market to form a complete market operation process. In the study period, the number of margin trading stocks reach 913, accounting for $32.5 \%$ of the total number of shares in the A stock market and have strong market representativeness. Further, the stock in margin trading is deleted, the long-term suspension, the ST processing and the delisting stock, and the final 743 stocks are selected as the research samples.

\section{B. Investors' Margin Trading Behavior Test}

1) Overconfidence test of investors' margin trading behavior

Barber and Odean [21] first propose the use of volume to measure confidence. Compared with volume, Statman [22] further research argues that the turnover rate can fully reflect the frequent trading of investors under overconfidence. In the current related research, most scholars use the turnover rate to measure Investor overconfidence. Accordingly, this paper examines the relationship between the rate of return and turnover rate of margin trading samples which based on the model and introduced by Salma and Ezzeddine [23]

$$
V_{\mathrm{t}}=\alpha+\beta \sum_{\mathrm{i}}^{T} R_{\mathrm{t}-\mathrm{i}}+\gamma \sum_{\mathrm{j}}^{J} V_{\mathrm{t}-\mathrm{j}}+\varepsilon
$$

Here: $V_{\mathrm{t}}$ is the turnover rate; $R_{\mathrm{t}}$ is rate of return of margin trading at $t$ time.

Test the stability of the related variables, and the results are shown in Table 1.

\section{TABLE I. UNIT ROOT TEST}

\begin{tabular}{|c|c|c|c|c|c|c|}
\hline Variable & $\boldsymbol{A D F}$ test value & $\mathbf{1 \%}$ critical value & $\mathbf{5 \%}$ critical value & $\mathbf{1 0 \%}$ critical value & $\boldsymbol{P}$ value & conclusion \\
\hline $\boldsymbol{V}$ & -3.214020 & -3.451421 & -2.870712 & -2.571728 & 0.0201 & instability \\
\hline $\boldsymbol{d} \boldsymbol{V}$ & -17.57173 & -3.451421 & -2.870712 & -2.571728 & 0.0000 & stability \\
\hline $\boldsymbol{R}$ & -14.36775 & -3.451283 & -2.870651 & -2.571695 & 0.0000 & stability \\
\hline
\end{tabular}

After $A D F$ test, $R$ is stable at $1 \%$ significant level, and $d V$ is

stable after first order difference. Using the research of 
Statmans weekly data of the US stock market, the turnover rate and rate of return daily data of the margin trading are lagged by
5 order regression results are shown in Table 2 as follows:

TABLE II. LEGGED 5 ORDER REGRESSION RESULT

\begin{tabular}{|c|c|c|c|c|c|c|c|c|c|c|c|}
\hline Parameter & $\boldsymbol{\alpha}$ & $\boldsymbol{\beta}_{\mathbf{1}}$ & $\boldsymbol{\beta}_{\mathbf{2}}$ & $\boldsymbol{\beta}_{\mathbf{3}}$ & $\boldsymbol{\beta}_{\mathbf{4}}$ & $\boldsymbol{\beta}_{\mathbf{5}}$ & $\boldsymbol{\gamma}_{\mathbf{1}}$ & $\boldsymbol{\gamma}_{\mathbf{2}}$ & $\boldsymbol{\gamma}_{\mathbf{3}}$ & $\boldsymbol{\gamma}_{\mathbf{4}}$ & $\boldsymbol{\gamma}_{\mathbf{5}}$ \\
\hline estimation & -0.01 & -1.80 & $17.86^{* * *}$ & -3.12 & 0.94 & 0.83 & $-0.35^{* * *}$ & $-0.26^{* * *}$ & -0.10 & -0.09 & $-0.14^{* *}$ \\
\hline
\end{tabular}

Note: $* * *$ is $1 \%$ significant level; $* *$ is $5 \%$ significant level; * is $10 \%$ significant level.

From Table 2, $d V(-1)$ and $d V(-2)$ have a significant negative impact on $d V$ in the sample period when the high turnover rate in the previous period has a negative impact on the turnover rate of this period, indicating that there is a self-correction mechanism in the process of overtrading. At the same time, the effect of $R(-2)$ on $d V$ is remarkable, which shows that margin trading rate of return has a significant favorable effect on the turnover rate, the higher rate of return, the more frequent investors' margin trading. And the previous margin trading sample returns will enhance the overconfidence of investors in the next margin trading.

\section{2) Herd effect test of investors' margin trading}

Compared to the two methods of $L S V$ and CSSD, Chang proposes a higher accuracy for herd effect measured by standard deviation of cross section income (CSAD) method and have been widely used in the academic field [24]. On the basis of that, this study further uses Ma in the CSAD model to add two items (formula 2) to test whether herd effect exists [25].

$$
\operatorname{CSAD}_{t}=\alpha+\gamma_{1}\left|R_{m, t}\right|+\gamma_{2} R_{m, t}^{2}+\varepsilon_{t}
$$

CSAD is the standard deviation of cross section incomes, and $R_{\mathrm{m}}$ is market return. If there is herding effect in margin trading, $\gamma_{2}$ should be significantly negative, and the larger the value, the more significant the herding effect. This paper uses the study samples and calculates the daily scatter plot of CSAD and $R_{\mathrm{m}}$ (Figure 2), there is no obvious linear relationship between $C S A D$ and $R_{\mathrm{m}}$, but there may be a herd effect based on the nonlinear relationship.

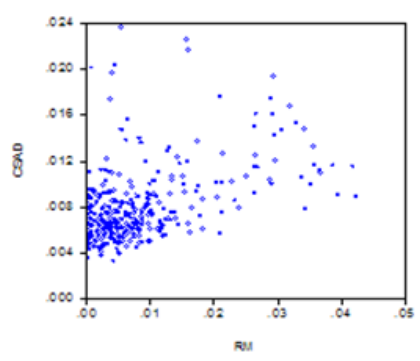

FIGURE II. CSAD AND RM DIAGRAM

Further, the herd effect is tested by Formula 2 to examine the existence of the herd effect of investors in the margin trading. The regression results are shown in Table 3 as follows:

TABLE III. CSAD REGRESSION RESULTS

\begin{tabular}{|l|c|c|c|}
\hline Parameter & $\boldsymbol{\alpha}$ & $\boldsymbol{r}_{1}$ & $\boldsymbol{r}_{2}$ \\
\hline estimation & $0.0073^{* * *}$ & $0.1469^{* * *}$ & $-3.0362^{* *}$ \\
\hline
\end{tabular}

From table 3 , the coefficient of $r_{1}$ is significantly favorable and the coefficient of $r_{2}$ is significantly negative under the significant level of $5 \%$, indicating that there is a significant herd effect of investors in the margin trading.

\section{Test of Disposing Effect of Investor's Margin Trading Behavior}

This paper uses the method of Zhai and Ren [26] to test the disposition effect of investor's margin trading behavior. First, the method is divided into two groups of sub samples based on the favorable and negative values of the $R_{\mathrm{n}-1}$ (the previous day of the transactions). Then, the $V / R_{\mathrm{n}-1}$ values of the subsamples are calculated, and then test whether the independent variable $R_{\mathrm{n}-1}$ has statistically significant effect on dependent variables $V$ (Change ratio of the next transactions day) in subsamples. According to the sample, subsamples with $R_{\mathrm{n}-1}>0$ (sample size
124 ) and subsamples of $R_{\mathrm{n}-1}<0$ (sample size 125) are shown in Table 4 as follows:

Regression analysis of subsamples is used to test whether the effect of $R_{\mathrm{n}-1}$ on $V$ (parameter $r_{l}$ ) is statistically significant. The regression results are shown in Table 5 as follows:

From the above regression results, no matter $R_{\mathrm{n}-1}>0$ or $R_{\mathrm{n}-1}$ $<0$, the effect of $R_{\mathrm{n}-1}$ on the statistical significance of margin trading samples is favorable and significant, and when the stock price of margin trading samples is favorable, the margin trading volume of the next trading day is more obvious. This conclusion is consistent with the inference of disposition effect, which indicates that investors tend to hold losses and sell profits in margin trading. 
TABLE IV. SUBSAMPLE LIST

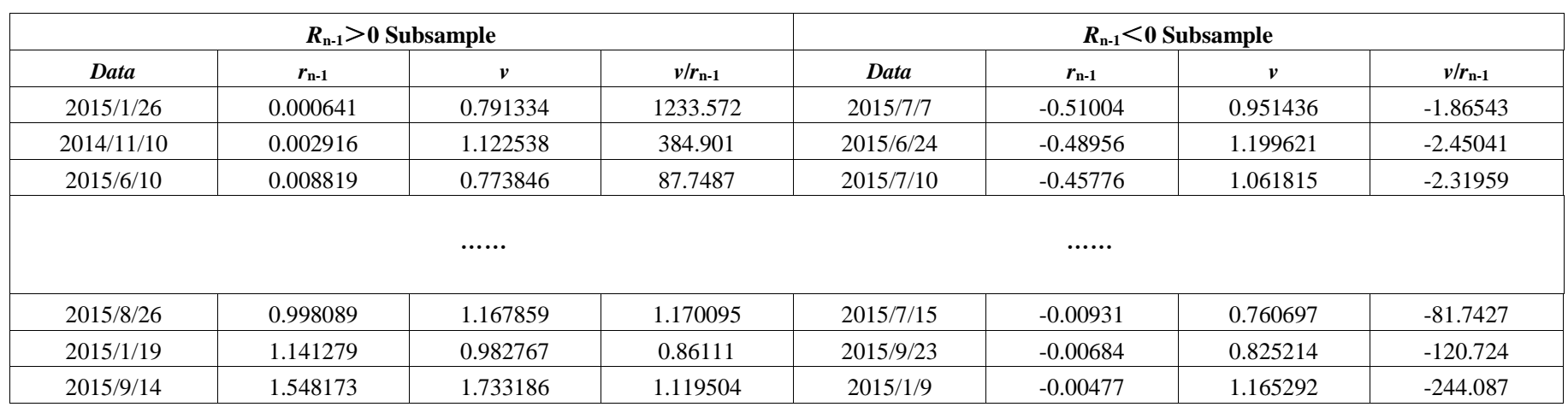

TABLE V. SUBSAMPLE REGRESSION RESULTS

\begin{tabular}{|c|c|c|c|}
\hline & $\boldsymbol{a}$ & $\boldsymbol{r}_{\mathbf{1}}$ & $\boldsymbol{V} /\left|\boldsymbol{R}_{\mathrm{n}-\mathbf{1}}\right|$ \\
\hline $\boldsymbol{R}_{\mathrm{n}-\mathbf{1}}>\mathbf{0}$ & $1.0933^{* * *}$ & $0.3382^{* * *}$ & 24.95575 \\
\hline $\boldsymbol{R}_{\mathrm{n}-\mathbf{1}}<\mathbf{0}$ & $0.9893^{* * *}$ & $0.1463 *$ & 21.12515 \\
\hline
\end{tabular}

\section{Simulation Simulation OF INVESTORS' MARGIN TRADING BEHAVIOR}

Drawing on the research ideas of Dai [27], this paper constructs an artificial stock market consisting of three parts, namely the market, the trading match mechanism and the traders. In order to analyze the behavior patterns of different types of investors in the margin trading, the investors are divided into basic analysis traders, technical analysis traders and noise traders in three categories, and each type of investors is the same (samples 10), and suppose that investors have CARA utility function that investors can constantly learn and adjust their investment strategies according to market changes.

\section{A. Simulation and Simulation Design}

\section{1) Market design}

The setting of dividend flow follows the formula 3 process which is generated by external stochastic processes. And the basic analysts react to dividends.

$$
\mathrm{d}_{t}=\bar{d}+\rho\left(d_{t-1}-\bar{d}\right)+\varepsilon_{t}
$$

Where, $d_{\mathrm{t}}$ is dividend of the stock in the t period, $\bar{d}$ is a long term dividend, $\rho$ is correlation coefficient between the current dividend and the previous dividend, $\varepsilon_{\mathrm{t}}$ is random variable that follows the normal distribution $N\left(0, \sigma^{2}\right)$.

According to the current system, the margin ratio must be greater than or equal to $50 \%$ in the market design, and if less than $50 \%$ can't open; the guarantee ratio is greater than or equal to $130 \%$, when the proportion is less than that proportion, the position of the trader's position will be forced selling.

\section{2) Design of transactions matching mechanism}

According to the current trading board system, the rise and fall range is set to $10 \%$; the model also sets the liquidation system according to the current margin trading system, adopts the no margin trading to carry out $T+1$ liquidation, while the margin trading adopts $T+0$ liquidation.

\section{3) Design of traders}

Suppose that technical analysis traders use the average strategy for learning and adjustment. Noise traders have no specific investment strategies, and their quotations follow the normal distribution within the range of the rise and fall, and the basic analysis traders based on genetic algorithm to study and adjust the dividend strategy through studying dividend flow. The investment income of traders participating in financing transactions and margin trading in the $t$ period is shown in formula 4 and formula 5 respectively.

$$
\begin{gathered}
e=\frac{E_{i, t}\left(p_{t+1}+d_{t+1}\right)}{p_{t}}-1 \\
e=1-\frac{E_{i, t}\left(p_{t+1}+d_{t+1}\right)}{p_{t}}
\end{gathered}
$$

Here, $E_{i t}$ is the expectation of investors in the $t$ period to $t+1$ stock price and dividend, and $P_{\mathrm{t}}$ is the current stock price.

Suppose that the three types of traders have a risk aversion attitude and $C A R A$ utility function, that is $u_{\mathrm{c}}=-\mathrm{e}^{-\lambda c}, \lambda>0$ indicates absolute risk aversion coefficient. Agent $t_{\mathrm{i}}$ expects the running state of the stock market in the $t$ period to $t+1$ :

$$
E_{i, t}\left(p_{t+1}+d_{t+1}\right)=a *\left(p_{t}+d_{t}\right)+b
$$

$a, b$ is parameter. When the normal distribution is expected, the $C A R A$ utility function is used to calculate the amount of stock held by $i$ trader: 


$$
X_{i, t}=\frac{E_{i, t}\left(p_{t-1}+d_{t-1}\right)-p_{t}(1+t)}{\lambda \sigma_{i, t p+d}^{2}}
$$

$$
\sigma_{\mathrm{i}, t \mathrm{p}+d^{2}} \text { is expected variance. }
$$

The first order derivation of formula 7 is used to calculate of marginal demand such as formula 8 :

$$
\frac{\partial x_{i, t}}{\partial p}=\frac{a-r-1}{\lambda \sigma_{i, t p+d}^{2}}
$$

When the marginal demand of formula 8 is favorable, it means that the trader declared the purchase, while on the contrary, it means that the trader declared the sell. When the margin trading is not introduced in the market, the amount of buying and selling of the stock is limited by the amount of cash held by the traders and the number of securities. When the market is introduced into the market, the amount of buying and selling of the stock is limited by the margin ratio and the guarantee ratio. The trader determines that the price of the report is based on the expectation of the stock price and dividend, determined by the parameter a and $\mathrm{b}$, using the CARA utility function to determine the expected holdings and the entrustment declaration of the stock, and the price of the report is determined by the parameters $a, b$ and $e$, and $\lambda$ is assumed to be constant.

\section{B. Simulation Results and Analysis}

\section{1) Histogram statistics}

$R$ software is used to simulate the no margin trading, margin trading, pre-learning without margin trading and pre-learning has margin trading through the above design, and the simulation value of the volatility index is calculated by the index model.

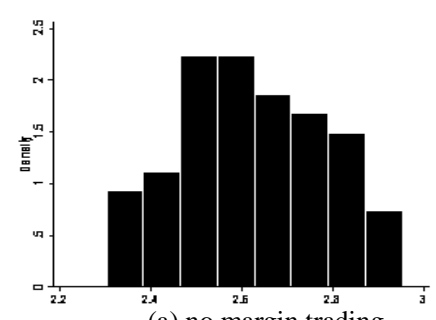

${ }^{24}$ (a) no margin trading

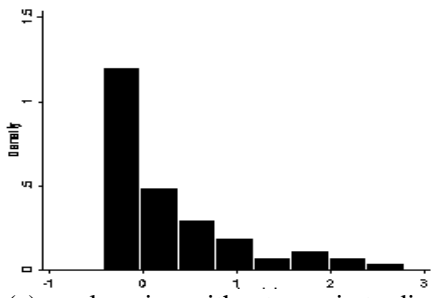

(c) pre-learning without margin trading

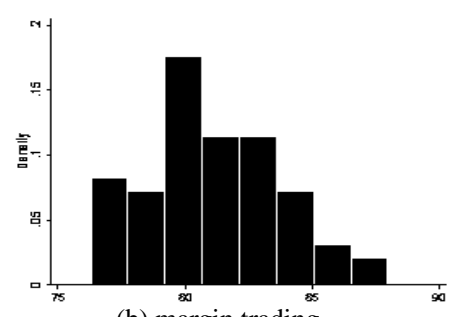

(b) margin trading

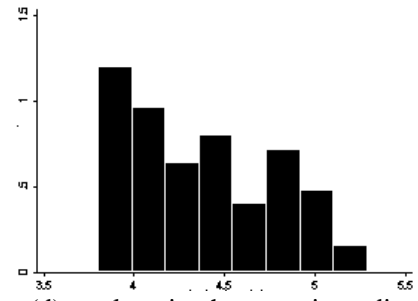

(d) pre-learning has margin trading
FIGURE III. HISTOGRAM

From figure 3 , the four kinds of transactions have the right deviation. The normal distribution and the uniform distribution are widely used. The lognormal distribution, the Gamma distribution, the Weibull distribution and the Cauchy distribution are the most common right partial distributions. Four kinds of transactions are used to test the similarity of each distribution, and the final distribution is determined according to $K-S$ test.

\section{2) Determining the distribution of all kinds of transactions}

First, the density function curves of Normal, Uniform, Lognormal, Gamma, Weibull and Cauchy are superimposed on the histogram of all kinds of transactions (omit). Then the maximum likelihood estimation method is adopted to estimate the possible distribution parameters. The estimated results are

\begin{tabular}{|c|c|c|c|}
\hline \multicolumn{2}{|c|}{ No margin trading } & \multicolumn{2}{|c|}{ margin trading } \\
\hline Distribution of fitting & Parameters of distribution & Distribution of fitting & Parameters of distribution \\
\hline Normal & $\mu=445.52 \quad \delta=170.70$ & Normal & $\mu=81.16 \quad \delta=2.68$ \\
\hline Uniform & $a=200.90 \quad b=898.90$ & Uniform & $a=88.00 \quad b=76.30$ \\
\hline Gamma & $\alpha=7.32 \quad \beta=0.02$ & Gamma & $\alpha=900.55 \quad \beta=11.09$ \\
\hline Lognormal & $\mu=6.03 \quad \delta=0.37$ & Lognormal & $\mu=4.39 \quad \delta=0.03$ \\
\hline Weibull & $\alpha=2.76 \quad \beta=500.52$ & Weibull & $\alpha=30.22 \quad \beta=82.48$ \\
\hline Cauchy & $\mu=388.08 \quad \delta=92.96$ & Cauchy & $\mu=80.89 \quad \delta=1.69$ \\
\hline \multicolumn{2}{|c|}{ pre-learning without margin trading } & \multicolumn{2}{|c|}{ pre-learning has margin trading } \\
\hline Distribution of fitting & Parameters of distribution & Distribution of fitting & Parameters of distribution \\
\hline Normal & $\mu=0.27 \quad \delta=0.71$ & Normal & $\mu=72177.36 \quad \delta=53811.87$ \\
\hline Uniform & $a=2.79 \quad b=-0.43$ & Uniform & $a=198937.60 \quad b=6330.00$ \\
\hline Gamma & N/A & Gamma & $\alpha=1.34 \quad \beta=79140.00$ \\
\hline Lognormal & $\mu=4.39 \quad \delta=0.03$ & Lognormal & $\mu=10.84 \quad \delta=0.91$ \\
\hline Weibull & N/A & Weibull & $\alpha=1.34 \quad \beta=79140.00$ \\
\hline Cauchy & $\mu=80.89 \quad \delta=1.69$ & Cauchy & $\mu=56814.18 \quad \delta=38098.59$ \\
\hline
\end{tabular}
shown in Table 6.

TABLE VI. ESTIMATION RESULTS OF VARIOUS TRANSACTIONS PARAMETERS 
The $K$-S test is performed on the above distribution at $5 \%$ significance level, and the results are shown in Table 7.

\section{3) Standard deviation contrast}

In view of the above four distributions, the standard deviation of stock prices is calculated at the significant level of $1 \%$ (Table 7) as follows:

TABLE VII. STANDARD DEVIATION OF STOCK PRICE

\begin{tabular}{|c|c|c|c|c|}
\hline & No margin trading & margin trading & $\begin{array}{c}\text { pre-learning without margin } \\
\text { trading }\end{array}$ & $\begin{array}{c}\text { pre-learning has margin } \\
\text { trading }\end{array}$ \\
\hline $\begin{array}{c}\text { Standard deviation } \\
\text { mean }\end{array}$ & 25.035 & 76.704 & 46.58 & 22.12 \\
\hline
\end{tabular}

From table 7, the volatility of the stock price in the margin trading is obviously greater than that of the no margin trading in the case of no pre-learning, which shows that the introduction of the margin trading will increase the volatility of the stock price to a certain extent, and the reason possible behind it is the overconfidence in the process of the investors' behavior, the existence of disposition effect and herding effect that will increase the impact on stock price when combined with the leverage function of the margin trading. After eliminating the bias caused by the learning process, under the condition of prelearning, the fluctuation of stock price caused by the margin trading is less than no margin trading, which shows that the traders can reduce the irrational behavior in their own investment through the pre-learning process and make the twoway trading function of the margin trading become a market stabilizer to some extent, which also shows that the margin trading itself is neutral as a system variable, and its impact on the stock market depends on the rationality of investor behaviors.

\section{CONCLUSION}

Investors have significant overconfidence, disposal effect and herd effect in the process of the margin trading through the theoretical analysis and quantitative study of China A stock market, which shows that the margin trading with the characteristics of short trading and leveraged transactions may become the cause of excessive volatility in the stock market. In further simulation studies, the introduction of the margin trading tends to increase market risk and can hedge and reduce the market volatility by pre-learning. At the same time, the income level of the three types of traders, including the basic analysis traders, technical analysts and noise traders, have been promoted to some extent after the introduction of the margin trading, in which the income level of the technical analyst is the most significant and the noise trader is always the lowest and lowest negative for all traders.

\section{ACKNOWLEDGEMENT}

The authors sincerely acknowledge that this work was financially supported jointly by Natural Science Basic Research Program of Shaanxi, China (2017JM7015).

\section{REFERENCE}

[1] Odean T. Are investors reluctant to realize their losses?[J]. The Journal of finance, 1998, 53(5): 1775-1798.

[2] Frazzini A. The disposition effect and underreaction to news[J]. The Journal of Finance, 2006, 61(4): 2017-2046.

[3] Rau H A. The disposition effect in team investment decisions: Experimental evidence[J]. Journal of Banking \& Finance, 2015, 61: 272282.

[4] Kaustia M. Prospect theory and the disposition effect[J]. Journal of Financial and Quantitative Analysis, 2010, 45(3): 791-812.

[5] Odean T. Do investors trade too much?[J]. Available at SSRN 94143, 1998.

[6] Tan Songtao. Self attribution bias, learning and stock overconfidence [J]. economic theory and economic management, 2013, (11): 71-79.

[7] Liao Li, he Pei Fei, Zhang Weiqiang, Shen Hongbo. Research on the overconfidence and over trading of Chinese individual investors [J]. investment research, 2013,32 (08): 35-46.

[8] Liu Bo, Zeng Yong, Tang Xiao I. An Empirical Study on herding effect in China's stock market [J]. operations research and management, 2004, (01): 87-94.

[9] Li Zhiwen, Yu Peikun, Yang Jing. Differences in herding behavior between institutional investors and individual investors [J]. financial research, 2010, (11): 77-89.

[10] Cheng Tian Xiao, Liu Liya, Guan Yi Zhong. An empirical study of herding behavior between QFII and domestic institutional investors [J]. management science, 2014,27 (04): 110-122.

[11] Zheng Feng, Zhao Wenyao, Zhang Shulin. Herding behavior research based on Agent [J]. Chinese management science, 2015,23 (S1): 424-429.

[12] Arthur W B, Holland J H, LeBaron B. Asset pricing under endogenous expectations in an artificial stock market[J]. 1996.

[13] Zou Lin, Ma Chaoqun, Yang Xiaoguang, Zhou Zhongbao. Effect of dividend payment rate on stock price based on Agent different trading systems, [J]. system engineering, 2011,29 (10): 7-13.

[14] Wu Shu, Li Xindan, Zhang Bing. The influence of short selling on stock market based on computational experiments [J]. management science, 2013,26 (04): 70-78.

[15] Liu Shaobo, Cui Ping. Limited arbitrage and its equilibrium in the capital market. [J]. economics dynamics, 2005, (09): 111-115.

[16] Chi Lixu, Zhuang Xintian. An investor's irrational behavior deviation and stop strategy -- An Empirical Study of the disposal effect and reference price perspective; [J]. Journal of management science, 2011,14 (10): 5466.

[17] Louwers T J, Messina F M, Richard M D. The Auditor's Going - Concern Disclosure as a Self - Fulfilling Prophecy: A Discrete - Time Survival Analysis[J]. Decision sciences, 1999, 30(3): 805-824. 
[18] Chen Guojin, mak. The rational behavior of investors facing bubbles: selling, watching or riding? [J]. Shanghai economic research, 2012,24 (03): 84-92.

[19] Xu Nian hang, Yu Yao, Yi Zhihong. Institutional investor herding behavior and stock price collapse risk [J]. manage the world, 2013, (07): $31-43$.

[20] Liu Xiangdong, Liu Cheng, Liu Shancun, Lu Jiajun. Herding behavior exacerbates stock price volatility? [J]. systems engineering theory and practice, 2014,34 (06): 1361-1368.

[21] Barber B M, Odean T. Boys will be boys: Gender, overconfidence, and common stock investment[J]. The quarterly journal of economics, 2001, 116(1): 261-292.

[22] Statman M, Thorley S, Vorkink K. Investor overconfidence and trading volume[J]. The Review of Financial Studies, 2006, 19(4): 1531-1565.

[23] Salma Z, Ezzeddine A. Overconfidence And trading volume: Evidence from an emergent market[J]. Annales Universitatis Apulensis Series Oeconomica, 2008, 1(10): 21-41.

[24] Chang E C, Cheng J W, Khorana A. An examination of herd behavior in equity markets: An international perspective[J]. Journal of Banking \& Finance, 2000, 24(10): 1651-1679.

[25] Ma Li. An empirical analysis of herding effect in China's stock market [J]. Nankai economic research, 2016, (01): 144-153.

[26] Zhai Hongsen, Ren Da. An empirical analysis on the disposition effect of Shanghai stock index A [J]. Journal of Chongqing University of Technology (NATURAL SCIENCE), 2016,30 (07): 149-156.

[27] Dai Qin, Xie Fei, Yan Guang le. The influence of China's margin trading system on stock market volatility based on Swarm platform [J]. Shanghai economic research, 2014, (09): 31-39. 